\title{
Vocational evaluation and vocational guidance for young people with a history of drug abuse
}

\author{
Andrew M.H. Siu ${ }^{\mathrm{a}, *}$, Manfred S.M. Fung ${ }^{\mathrm{a}}$, Phoebe P.P. Cheung ${ }^{\mathrm{a}}$, Chi Kwan Shea ${ }^{\mathrm{b}}$ \\ and Benson W.M. Lau ${ }^{\mathrm{a}}$ \\ ${ }^{a}$ Department of Rehabilitation Sciences, The Hong Kong Polytechnic University, Hong Kong \\ ${ }^{\mathrm{b}}$ Department of Occupational Therapy, Samuel Merritt University, Oakland, CA, USA
}

Received 10 August 2017

Accepted 24 June 2018

\begin{abstract}
.
BACKGROUND: Young people recovering from drug addiction often face challenges in returning to the job market and in maintaining their jobs. Many of them feel they have no choice but to do entry-level work, and they are often unsure about their work ability and vocational choice.

OBJECTIVE: In collaboration with a youth outreach service, this study aims to provide a package of vocational assessment, guidance, and support for these clients.

METHODS: Using a strength-based case management framework, we conducted a comprehensive vocational evaluation for each participant $(\mathrm{N}=17)$, which covered self-perception of abilities, work and occupational interests, work readiness, work-related self-efficacy, and work aptitudes. We presented assessment results to each client and provided guidance on their education, training, or vocational choice.

RESULTS: The results of aptitude tests indicate that most participants can cope with an entry-level job. Many participants are strong in jobs that require quick decision-making, sorting, assembly, and clerical tasks, but many are weak in fine manual dexterity and eye-hand-foot coordination. Many participants preferred jobs that are creative, indefinite, and autonomous in nature.

CONCLUSION: Longer-term vocational counseling and coaching is needed to help clients make vocational choices and extend their job tenure. Many clients will also need training in job seeking and job maintenance skills.
\end{abstract}

Keywords: Substance abuse, assessment, guidance, chinese, vocational

\section{Introduction}

Illicit drug abuse and drug dependence has a major impact on the work motivation and employability of young people [1-3]. People who are recovering from drug addiction or have recently stopped taking drugs face major challenges in returning to the work, finding a job, or deriving satisfaction from work [4, 5]. In Hong Kong, a recent local government

\footnotetext{
*Address for correspondence: Dr. Andrew M.H. Siu, Department of Rehabilitation Sciences, The Hong Kong Polytechnic University, Hunghom, Kowloon, Hong Kong SAR. Tel.: +852 27666753; E-mail: a.siu@ polyu.edu.hk.
}

report suggested that newly reported drug abusers on average started to abuse drugs at 23 years old, and they had abused drugs for at least 2.4 years before their first report. Fifty-one percent attained lower secondary education (junior high school). Only $35 \%$ of the program participants were full-time workers, and $17 \%$ were part-time or casual workers [6]. Several factors may significantly affect the employability and job tenure of persons with a history of drug abuse. First, long-term drug abuse can affect the neurocognitive abilities and everyday functional abilities that are necessary for gainful employment [7, 8]. Second, many persons with a history of drug abuse 
have co-occurring psychological disorders (such as depression or post-traumatic stress disorder) that interfere with work performance and work readiness, leading to issues in sustainability of employment [9]. Third, many individuals feel lost and unsure about what kind of job or vocational training may be suitable for them. Drug use interrupts both school and work participation, and many adolescents who abuse drugs have little or unstable work experience [10]. Quite a number of individuals left school by junior high school, so they may not have a good enough understanding of their strengths to develop a mature career choice [11]. Many may have lost or never gained the skills and discipline necessary for sustained employment [2]. In addition, some persons with a history of drug abuse engaged in criminal activities (such as drug trafficking), which brings a large income that supported their drug habit $[1,12]$. Because of their lack of vocational skills, many find it challenging to meet the requirements of entry-level jobs, many of which provide an income that is barely sustainable for their lifestyle.

There are several studies and vocational training options available for young people with a history of substance abuse, who many have left school before Secondary 3 (9th grade). The Hong Kong SAR government offered 9 years of free compulsory education from Primary 1 to Secondary 3 (1st to 9th grade). Most adolescents would reach 15 when they finish Secondary 3 , and they could be legally employed for work at 15 years old. Students could also choose to engage in Applied Learning Courses (formerly called Career-oriented Curriculum Courses) in secondary schools, or vocational training institutes. For young people who want to pursue higher qualifications in tertiary education, they could join the Youth Employment and Training Programme (YETP), which is a "comprehensive platform of job search with onestop and diversified pre-employment and on-the-job training for young school leavers aged 15 to 24 with educational attainment at sub-degree level" [13]. The completion of these types of vocation-oriented programs enables the young person to engage in further vocational training or education in preparation for their career.

Many clinical guidelines and major reviews of government-funded substance abuse programs have reiterated that vocational counseling and rehabilitation are essential for substance abusers [1, 3]. However, employment support is often unavailable for people recovering from addictions [14]. In substance abuse rehabilitation programs, social work interventions and peer support programs are often integrated with vocational rehabilitation to improve treatment outcomes [2], and career development activities could be meaningful interventions for substance abusers [14]. In particular, strength-based case management in vocational rehabilitation could lead to more positive employment outcomes [15].

This study aims to address several gaps in understanding the challenges of the vocational rehabilitation of persons with a history of drug abuse. First, few studies have documented the personal and vocational strengths of people recovering from substance abuse. While there is evidence that drug abuse may affect cognitive abilities and emotional adjustment, it is not clear if productivity is compromised to the point that persons recovering from drug abuse can only cope with entry-level jobs. This study aims to conduct a more comprehensive and standardized evaluation of clients' aptitudes, work readiness, and career maturity. The valuation results would help us to identify strategies for promoting work readiness and vocational choice among clients.

Second, few studies document how young persons with a history of drug abuse perceive their own strengths in work skills, vocational aspirations, work-related self-efficacy, and employability. We aim to conduct both in-depth interviews and selfcompleted questionnaires to obtain clients' views on these aspects.

Third, we provided vocational guidance to the participants, starting with presenting the vocational evaluation results to the participants. We would help the clients to check their self-perceptions of abilities and aptitude to objective evaluation results. We hope this could help participants increase their self-understanding. Fourth, we discussed possible vocational or education planning with the participants, and how they may manage some of the barriers to employability and employment. We hope that concrete and objective information from the vocational evaluations will facilitate the development of their vocational identity and vocational choice.

In sum, this study aimed to address several research questions: 1) What are the personal strengths and vocational aspirations of young persons who are recovering from addiction? 2) How far could the presentation of comprehensive objective vocational evaluation results help clients to develop better selfunderstanding and vocational identity? 3) How far could career guidance help clients to develop their vocational choice and plan for pursuing training or employment? 


\section{Method}

\subsection{Research design}

This study uses a strength-based counseling and case study approach in understanding the vocational aspirations, strengths, career maturity, and work readiness of young people who are recovering from drug abuse or recently stopped taking drugs [16].

\subsection{Participants}

The participants $(\mathrm{N}=17)$ were recruited by social workers of a non-governmental organization in the Eastern district of Hong Kong. Most of the participants participated in the youth services provided by youth centers, outreach social work, or drug rehabilitation services in the district. There were several selection criteria in the recruitment of participants: They are aged 15 to 25 ; have a history of drug abuse of over one year, and have either significantly decreased drug use or stopped drug use entirely; and were independently motivated to volunteer to join a program aiming to promote their vocational readiness and employability. We briefed all potential participants about the purpose of the clinical assessment, guidance program, and the research study. Those who were willing to join the study were required to sign a consent form.

\subsection{Instruments}

The vocational evaluation in this study covered three areas: Vocational maturity and choice, including self-perceived aptitudes, acceptable working conditions, and occupational interests; aptitudes, such as non-verbal intelligence, fine motor skills and dexterity, problem solving, and eye-hand-foot coordination and physical capacity; and work readiness, including motivation, work history, and self-efficacy in returning to work. We employed a range of assessment tools including as semi-structure interview, self-completed questionnaires on work-related selfefficacy and employment readiness, standardized assessments on hand dexterity (Purdue Pegboard), VALPAR work sample.

\subsubsection{Semi-structured interview}

We conducted interviews with the participants to collect information regarding their work history, career interests, self-perceived work abilities, and values toward work. Based the work of Power [17,
18], we developed a semi-structured interview that guided participants to explore their interests in various activities, such as how much they like to deal with things and objects, people, processes, machines, and so on; their aptitudes, or their perceived ability in general learning, mathematics, fine motor coordination, lifting capacity, and so on; their preferred work conditions, or to what extent certain work conditions are acceptable to them, such as indoor, outdoor, temperature extremes, or hazards; and occupational interests. To measure this last aspect, we presented a range of twelve occupations groups listed in the Guide for Occupational Exploration (GOE) [19], and asked participants to choose a maximum of three occupation groups that they would consider as a vocational choice.

\subsubsection{The Work-Related Self-efficacy Scale (WRSS)}

The 37-item WRSS asks respondents to evaluate their own confidence in the four areas of work-related and career-related skills to use an efficacy scale of 1 to 10. Based on a sample of participants with severe mental illness, the validation study by Harris et al. [20] showed that the WSS had good face validity, very good test-retest reliability, and internal consistency. Exploratory factor analysis showed that the items are loaded on four factors, which are labeled as self-efficacy in career planning, job acquisition, work related social skills, and general work skills (the four subscales).

\subsubsection{Employment Readiness Scale (ERS)}

The ERS was developed to measure attitudes toward work, and how work attitudes may be linked to length of unemployment time [21]. The ERS developer invited directors from different human resources departments to identify the most relevant behaviors reflecting employment readiness. The ERS has 43 items rated on a 4-point Likert scale, which is used to evaluate the extent to which the individual agrees with each item. The study by Alfano [21] showed that the scale demonstrated a reliability of 0.87 (using the Spearman-Brown formula) and it could differentiate those who are currently employed, seeking employment, and chronically unemployed.

\subsubsection{Aptitude assessments}

We use a battery of tests for aptitude testing, including the Test of Non-Verbal Intelligence (TONI-3), the Purdue Pegboard, and the VALPAR Component Work Samples (VCWS). The TONI was developed to assess the aptitude of children and adults whose 
cognitive, linguistic, or motor skills might adversely affect their performance on traditional tests of intelligence or might prevent them from even understanding or responding to the material contained on such tests. The TONI-3 has 45-items on the test are arranged by increasing difficulty, and the test has two forms (A and B) [22]. Using either Form A or B, the examinees are requested to choose one of the pictures from the options that match with the missing grid in the question. Reviews of nonverbal instruments have shown that the TONI-3 is psychometrically sound [23].

The Purdue Pegboard was developed for employee selection in industrial jobs [24]. We used the Purdue Pegboard for assessing finger dexterity in this study, and the results were converted to percentiles and compared with local norms collected in mental health settings of Hong Kong.

We employed the VALPAR Component Work Samples (VCWS) [25], a set of standardized work samples for vocational and work evaluation, to assess participants' aptitude and competence in simulated situations that are close approximations of real work conditions $[26,27]$. We requested all participants to complete a minimum of two standard work samples: the VCWS 6 (Independent Problem Solving), which assesses the ability to perform work involving visual comparison and the proper selection of abstract designs; and the VCWS 7 (Multi-Level Sorting), which assesses the ability to make decisions while performing work tasks that require physical manipulation and visual discrimination of objects with different colors, letters, numbers, and combinations of these. We also selected one to two more VCWS work samples for participants to complete based on their expressed occupational interests and work histories. We interpreted the VCWS test results according to local norms collected in mental health settings. The interpretation of test results would provide some information on how far the participant's aptitude in the areas of their vocational interests.

\subsection{Procedures}

Social workers from youth service and addiction services centers in the district helped to recruit participants to join the assessment and guidance program. Social workers or research assistants explained the purpose and procedures of the study to potential participants. Those who agreed to join were required to sign a consent form. We requested participants to commit at least three hours to complete an in-depth interview and work assessments, plus a debriefing session on a second visit. During the second visit, the occupational therapist presented the work evaluation reports to the participants and discussed their potential plans for engaging in vocational preparation or employment.

\subsection{Data analysis}

For each participant, the case therapist analyzed the vocational assessment results, self-completed questionnaire, interview data, and case guidance notes in order to provide an interpretation of the strength and weaknesses of the participant's employability. A detailed case study report was prepared for each participant, highlighting the challenges, directions and goals in career choice, vocational preparation, or job hunting of each client.

A case study report was prepared for each participant, with reference to their test performance and interpretation (such as percentile scores), and the therapist's case notes on the guidance session. Summary statistics (e.g. median, mode) of on the participants' self-assessment of abilities, work interests, preferred working conditions, work sample test results, work-related self-efficacy, were generated for further analyses. We compiled summaries of the strengths and weaknesses related to employability, career choice, vocational preparation or job acquisition plans of the participants, based on a crossexamination of the case study reports.

\section{Results}

\subsection{Participant demographics}

Eight $(47.1 \%)$ participants were males and nine $(52.9 \%)$ were females. Like many young people abusing drugs in Hong Kong, most participants tried different drugs over the years. Almost all participants said they have stopped using drugs, or only used very occasionally with some friends. None of the participants reported any major sensory impairment, physical and mental disabilities that may interfere with work capabilities, although a few mentioned that they were "over-active" during childhood. The mean age was $17.9(\mathrm{SD}=1.6)$, and they had a mean of 9.7 years $(\mathrm{SD}=0.8$ ) of education (around Secondary 3, or ninth grade). Around half of the participants had left school during junior secondary school. The average full- or part-time work experience of participants was 14.0 months $(\mathrm{SD}=12.5)$, indicating a large variation 
in work experience among them. Except for three who were not employed, all the other participants had full- or part-time jobs in service industries, with occupations such as waitress or attendant in restaurants and bars $(n=5)$, salesperson $(n=3)$, and food preparation and cook assistants $(n=3)$. Other jobs $(n=3)$ included shop-keeping, cosmetic and beauty services, and Internet service agent.

\subsection{Self-understanding of aptitudes}

More than half $(66.7 \%)$ of participants perceived that they have poor or very poor language ability (English or Chinese), and 62.5\% regarded their mathematics abilities to be poor or very poor (Table 1). Most of the participants considered themselves as average in general learning ability, spatial ability, and clerical aptitude. Participants rated their physical and motor skills highly, such as in body agility $(77.8 \%$ rated good or very good), finger dexterity $(62.5 \%$ rated good or very good), and eye-hand coordination (50.0\% rated good or very good).

\subsection{Work and occupational interests}

The majority $(72.7 \%)$ of participants preferred a job that "brings recognition or appreciation by others" (Table 2). The second and third most important sources of job satisfaction were being able to produce something (58.3\%), and having autonomy or doing creative work (50\%). Participants' interests in these three types of jobs were much higher when compared to the other nine types. No participant was interested in a job that was "regular, repetitive, and systematic."

We then asked participants to select three occupational groups that they were interested in from the 12 occupational groups of the GOE (Table 2). The occupational interests of the participants tended to focus on only a few areas: Arts, Entertainment, and Media (47.1\%); Education, Health and Social Services (35.3\%); Business Details (23.5\%); and Recreation, Travel, and other Personal Services (23.5\%). Very few participants were interested in the occupational groups of Scientific, Plants and Animals, Machinery, and Industrial Production.

In the survey of working conditions, all participants considered working indoor to be suitable $(64.3 \%)$ or very suitable (35.7\%) (Table 3). There were $41.7 \%$ of participants who could accept work outdoors or in cold weather extremes (33.4\%). No participants thought that a humid working environment was suitable for them. Only $20 \%$ of participants would accept a job with heat extremes, noise and vibrations, hazards, or enclosed spaces with hazards.

\subsection{Work readiness and work-related self-efficacy}

From the results of the Employment Readiness Scale (ERS), we found that most of the participants were quite ready to go to work. The mean of the ERS scale was $134.14(\mathrm{SD}=13.50)$, and the mean percentage of the ERS was $78.71 \%(\mathrm{SD}=8.03)$. From the results of the Work-Related Self-Efficacy Scale, participants were quite confident about their own general work (task-related) skills $(\mathrm{M}=8.04, \mathrm{SD}=1.12)$ and work-related social skills $(\mathrm{M}=7.79, \mathrm{SD}=1.54)$, but less confident in their job securing skills $(M=7.31$, $\mathrm{SD}=1.57)$ and career planning skills $(\mathrm{M}=7.01$, $\mathrm{SD}=0.56$ ). Many participants said they did not know how to prepare documents for job applications, fill out an application form, or prepare a resume. Some said it was unnecessary to learn these job-seeking skills, as they are not needed for entry-level job applications. They often relied on friends' opinions or networking to apply for jobs. A few also mentioned that they previously had high but stable incomes from the trade and delivery of illicit drugs, and that it was very hard to adjust to jobs that only provided a minimum wage.

\subsection{Work aptitudes}

To assess aptitudes, we measured finger dexterity (Purdue Pegboard), non-verbal intelligence (TONI3 ), and work aptitudes (VALPAR). The results indicated that the finger dexterity of the participants $(n=8)$ was between poor to average, with $12.5 \%$ having poor ratings, $37.5 \%$ having below average ratings, and the rest having average ratings. For the results of the TONI-3 $(n=14)$, most participants $(71.4 \%)$ had average intelligence, and $14.3 \%$ were rated as having borderline or superior intelligence (Table 4).

Most participants, or $82.4 \%$ in the VCWS 6 (Independent Problem Solving) and 76.5\% in the VCWS 7 (Multi-Level Sorting), reached the "meet or may exceed" standard (above average to superior), and only $11.8 \%$ of participants reached the "does not meet A" standard (below average) in both tests. All eight participants (100\%) who took the VCWS 8 (Simulated Assembly) reached the "have met or may exceed" standard. Most (77.8\%) of the participants who took the VCWS 11 (Eye-Hand-Foot Coordination) were graded as "does not meet B" (62.5 percentile or lower, which is regarded as a below 
Table 1

Self-Assessment of Abilities

\begin{tabular}{lccccccc}
\hline Abilities & \multicolumn{9}{c}{ Self-Perception (\%) } & Median & Mode \\
\cline { 2 - 6 } & Very poor & Poor & Average & Good & Very good & & \\
\hline General learning ability & - & - & 75 & - & 25 & 3 & 3 \\
Language ability & 11.1 & 55.6 & 22.2 & - & 11.1 & 2 & 2 \\
Mathematics ability & 12.5 & 50 & 25 & - & 12.5 & 2 & 2 \\
Spatial ability & - & 14.3 & 57.1 & 14.3 & 14.3 & 3 & 3 \\
Clerical aptitude & 12.5 & 25.0 & 37.5 & 12.5 & 12.5 & 3 & 3 \\
Finger Dexterity & - & - & 37.5 & 25.0 & 37.5 & 4 & 3 \\
Body coordination & - & - & 62.5 & 25.0 & 12.5 & 3 & 3 \\
Body agility & - & 11.1 & 11.1 & 55.6 & 22.2 & 4 & 4 \\
Eye-hand coordination & - & - & 50.0 & 37.5 & 12.5 & 3.5 & 3 \\
\hline
\end{tabular}

Table 2

Work and Occupational Interests

\begin{tabular}{lcc}
\hline Interests in activities & Not interested (\%) & Interested (\%) \\
\hline 1. Dealing with things and objects & 75 & 25 \\
2. Involving contact with people for business & 75 & 25 \\
3. Of a routine, definite, organized nature & 100 & 0 \\
4. Involves direct personal contact, to help or deal with clients for other purposes & 75 & 25 \\
5. Brings recognition or appreciation by others & 27.3 & 72.7 \\
6. Concerned with people and the communication of ideas & 72.7 & 27.3 \\
7. Of a scientific and technical nature & 91.7 & 8.3 \\
8. Of an unusual, indefinite nature that requires creative imagination & 50 & 50 \\
9. That are nonsocial and involve the use of machines, processes, or methods & 83.3 & 16.7 \\
10. That brings personal satisfaction from working on or producing things & 41.7 & 58.3 \\
\hline Occupational Interests (GOE) & & 47.1 \\
1. Arts, Entertainment, and Media (Artistic) & 52.9 & 5.9 \\
2. Science, Math, and Engineering (Scientific) & 94.1 & 5.9 \\
3. Plants and animals & 94.1 & 11.8 \\
4. Law, Law Enforcement, \& Public Safety (Security) & 88.2 & 0 \\
5. Mechanics, Installers, \& Repairers (Machinery) & 100 & 5.9 \\
6. Industrial Production (Manufacturing) & 94.1 & 23.5 \\
7. Business Details (Office jobs) & 76.5 & 17.6 \\
8. Sales \& Marketing & 82.4 & 23.5 \\
9. Recreation, Travel, \& other Personal Services & 76.5 & 35.3 \\
10. Education, Health Care \& Social Services & 64.7 & 5.9 \\
11. General Management \& Support & 94.1 & 5.9 \\
12. Sports \& Performing Arts & 94.1 &
\end{tabular}

Table 3

Working Conditions

\begin{tabular}{|c|c|c|c|c|c|c|c|}
\hline \multirow[t]{3}{*}{ Abilities } & \multicolumn{5}{|c|}{ Opinion $(\%)$} & \multirow[t]{3}{*}{ Median } & \multirow[t]{3}{*}{ Mode } \\
\hline & (1) & (2) & (3) & (4) & (5) & & \\
\hline & $\begin{array}{c}\text { Cannot } \\
\text { accept }\end{array}$ & $\begin{array}{c}\text { Not } \\
\text { suitable }\end{array}$ & $\begin{array}{c}\text { No } \\
\text { opinion }\end{array}$ & Suitable & $\begin{array}{c}\text { Very } \\
\text { Suitable }\end{array}$ & & \\
\hline Indoor work & - & - & - & 35.7 & 64.3 & 4 & 4 \\
\hline Outdoor work & 8.3 & 16.7 & 33.3 & 41.7 & - & 3 & 4 \\
\hline Extremes of cold, plus temperature changes & 13.3 & 33.3 & 20.0 & 26.7 & 6.7 & 3 & 2 \\
\hline Extremes of heat, plus temperature changes & 20.0 & 53.3 & 6.7 & 20.0 & - & 3 & 2 \\
\hline Wetness and humidity & 7.1 & 71.4 & 21.4 & - & - & 2 & 2 \\
\hline Noise and vibrations & 26.7 & 46.7 & 6.7 & 20.0 & - & 3 & 3 \\
\hline Hazards & 13.3 & 26.7 & 40.0 & 20.0 & - & 3 & 3 \\
\hline Fumes, odors, toxic conditions, dust, and poor ventilation & 26.7 & 46.7 & 6.7 & 20.0 & - & 2 & 2 \\
\hline
\end{tabular}

average grade). Among the four participants who took the VCWS 19 (Dynamic Physical Capacity), three $(75 \%)$ had medium manual handling capacity (suit- able for store clerks; delivery and logistics), while one $(25 \%)$ had heavy manual handling capacity (suitable for construction jobs). 
Table 4

VALPAR Work Samples Test Results

\begin{tabular}{|c|c|c|c|c|c|c|}
\hline \multirow[b]{2}{*}{ VCWS } & \multirow[b]{2}{*}{$\mathrm{N}$} & \multicolumn{4}{|c|}{ Interpretation of test results $(\%)$} & \multirow[b]{2}{*}{ Median } \\
\hline & & $\begin{array}{c}(1) \\
\text { Does not meet } \\
\text { B }(67.5 \%>)\end{array}$ & $\begin{array}{c}(2) \\
\text { Does not meet } \\
\text { A }(62.5-87.5 \%)\end{array}$ & $\begin{array}{c}(3) \\
\text { Meet } \\
(87.5-112.5 \%)\end{array}$ & $\begin{array}{c}(4) \\
\text { Meet, may } \\
\text { exceed }(>112.5 \%)\end{array}$ & \\
\hline 2. Size Discrimination & 3 & 33.3 & 66.7 & - & - & 2 \\
\hline 6. Independent Problem Solving & 17 & - & 11.8 & 5.9 & 82.4 & 4 \\
\hline 7. Multi-Level Sorting & 17 & - & 11.8 & 11.8 & 76.5 & 4 \\
\hline 8. Simulated Assembly & 8 & - & - & - & 100 & 4 \\
\hline 9. Whole Body Range of Motion & 2 & - & 50 & - & 50 & 3 \\
\hline 11. Eye-Hand-Foot Coordination & 8 & 77.8 & 11.1 & 11.1 & - & 1 \\
\hline 19. Dynamic Physical Capacities & 4 & & & $\begin{array}{c}n=3 \\
\text { Medium duty }\end{array}$ & $\begin{array}{c}n=1 \\
\text { Heavy duty }\end{array}$ & \\
\hline
\end{tabular}

\subsection{Guidance process}

We compared the case reports and analyzed the guidance process of all the clients. Considering the aptitude test results and work behavior during testing, we estimated that $80 \%$ of the participants could meet the requirements of entry-level jobs. As the aptitude and simulated work tasks lasts for a maximum of one and a half hours, we could not observe the work habits and tolerance that could potentially undermine their job performance. Only around $30 \%$ of the participants could clearly state specific career interests or choice during the interview, as we discussed with them what they wrote in the self-completed questionnaires. Most participants agreed that they wish to explore their career interests and choice further, or to understand more about the job market and employment opportunities. We noticed that $60 \%$ of male and $80 \%$ of female participants are expressive, sociable, and outgoing during the interviews, and many could give a good impression in brief job interviews. Thirty-five percent of the participants could only accept working conditions that are indoor, air-conditioned, quiet, comfortable, and with minimal occupational risks. The therapists need to encourage them to consider more types of work conditions (e.g. higher and lower temperature, noise levels, risks), which could open more job opportunities for them. On average, participants were willing to attend three to six months of in-service training for their job. About half (50\%) of the participants were willing to attend on-the-job training for over six months and up to two years, and only two are willing to pursue a diploma or certificate in vocational training institute.

\section{Discussion}

The results of the work sample and aptitude tests (VCWS 6 and 7) showed that most participants would appear to manage entry-level jobs, such as those in fast food or restaurants, retail and sales, and supermarkets. However, only part of the participants' self-perceptions matched the work assessment tests. The participants' perceptions that they were average in general learning and clerical aptitude were consistent with the results of work sample tests (VCWS 6,7 , and 8 ). They rated their body agility and manual dexterity as above average, but the work sample (VCWS 11) and manual dexterity (Purdue Pegboard) tests showed that most participants had below average or poor performance in these two aspects. These results showed that the participants tended to overestimate their motor abilities. It was interesting to note that many participants recalled that they were strong in physical exercise and activities when they were young. Some were a bit surprised that they were not doing well in manual dexterity or eye-hand-foot coordination tests. When we guided them to consider career options by examining their interests and abilities, many participants thought that it was possible for them to develop in the areas of sports, the performing arts, and entertainment.

Consistent with the aptitude tests results, the Employment Readiness Survey results suggested that the majority of participants were very much ready for work. Many tended to be more confident about their task-related and social performance at work, and less confident about selecting jobs, job-hunting, and securing a job. This is consistent with the unstable work histories they reported. Their average job tenure was short (usually one to three months), and on average their total work experience was just over one year (14 months). Overall, many participants were work-ready, and the task-related and social skills for full-time employment in entry-level jobs, but they need support to strengthen their job-seeking skills and job maintenance skills. 
Around one-third of the participants could not accept working conditions with extremes of temperature, high humidity, high noise levels, or have occupational hazards. While most preferred to work indoors, around $75 \%$ did not have strong opinion or find it suitable to work outdoors. During guidance sessions with the participants, we emphasized that jobs that have less comfortable work environments often have more training and career opportunities. We would give them examples of some jobs that have great career prospects in Hong Kong, if they could work outdoors and in high places, e.g. making bamboo scaffoldings. Some were also interested in learning to become a cook or in working in kitchens, and we need to help them anticipate working in a hot and humid environment.

Many participants perceived themselves as poor in the Chinese and English language as well as Mathematics; many recalled their frustrations with these foundation subjects. In fact, failures in these subjects contributed to their dropping-out from school during junior secondary school. Without completing senior secondary (high) school, they could not meet the basic requirement for many types of vocational training in Hong Kong [13]. During guidance sessions, we note that the participants became more willing to join the career-oriented study programs (like the YETP) once they understood it was career-oriented and could offer job placements that could become employment opportunities.

During guidance sessions, many participants were reluctant to express their work interests or career choice. They are worried about their academic background and history of drug abuse, and many felt that they are not eligible to consider a career or a job that is above entry level. "Art, Entertainment, and Media" was the only occupational group in the GOE survey that almost half of the participants were interested in. This is consistent with their strong need to have a job that brings recognition and appreciation; a job that is unusual, indefinite, and requires creative imagination; or a job that results in a product. From the vocational guidance sessions, quite a number of participants found that a career in the creative arts, sports coaching, dancing, or tourism would be attractive to them. During the guidance sessions, it was important that we helped participants understand more about different occupational groups. The participants will further benefit from talking to workers in different occupational groups, doing job visits, and actually trying out jobs in some settings.
Most of the participants greatly appreciated that we conducted the detailed assessments with them, which enable them to have more understanding about their work aptitudes and interests, Most of them said they have not received similar vocational assessment or guidance in their recovery process. They also appreciated the chance to discuss their training and career options, in view of their unfavorable educational background and unstable work record. During the guidance sessions, many discussed issues from the workplace, such as relationships with supervisors and co-workers, why they change jobs so frequently, or why they would like to go back to work now.

In Hong Kong, formal and informal career counseling programs and individual/group guidance are delivered by career teachers and social workers toward end of Secondary 3 [28-30]. This is the time when students need to consider their study stream in senior secondary (high) school, and such programs will continue in high school. However, most of our participants have left school before end of Secondary 3, and thus unable to benefit from such school services. There were also very few attempts to apply career counseling and development strategies to young people who are recovering from drug and substance addiction. The current vocational assessment and guidance strategies used in this study could address the core issues of underachievement and disengagement of young people recovering from addiction and tried to help them rebuild their meaning of life through vocational training and employment [31].

\subsection{Study limitations}

The study is unique in providing detailed vocational assessment results and guidance recommendations for young people recovering from drug addiction. However, the current study assessment results and suggestions for guidance are based on a small clinical sample of 17 clients recruited from several districts of Hong Kong, and may not be directly generalized to similar client groups in other parts of Hong Kong or around the world. The vocational assessment process takes much time and effort for the participants to complete. To keep the two to three-hour assessment acceptable to the participants, we allowed participants to select some aptitude and work sample tests. Thus some tests were completed by more participants (such as the VCWS simulated assembly), and others were completed by only a few (such as the VCWS 9, Whole Body Range of Motion). We cannot arrive at generalizable interpretations from 
the aptitude test results as some completed by only a few participants. We found it hard to report on the details of the participants' education and work histories. Few of them brought formal documents on their education and work history to the interview or guidance sessions meetings, and many said they could not recall details of their education and school life that occurred more than 5 years ago.

\subsection{Recommendation for practice}

As many participants left school during junior secondary school, their education background could become a barrier for them to pursue a career beyond entry-level jobs. Many would need to complete a hybrid type of youth employment and education program that could open new opportunities for vocational and technical training. Recovery services in addiction need to help young people understand career-oriented training programs could form a bridge to vocational training for specific careers. Many participants would need lots of encouragement and coaching to engage in new learning or training activities, as many of them felt that it was too late to start anything or felt discouraged because of frustrating experiences with school and academic achievement in the past. Addiction services will need to build their employer network to provide on-the-job training, apprenticeships, and career-oriented training programs that are closely linked to prospective jobs. We also noted that there were often discrepancies between participants' perceptions of their own abilities and interests, when compared with their tests performances. Vocational guidance should help clients to appreciate their strengths in employability. Many clients will also need guidance in job maintenance skills, such as relating with authority figures, and in managing emotions and conflicts in the workplace. Such training would help them to secure their job and extend their job tenure.

\section{Conclusion}

Based on the results of this study, we suggested that longer-term vocational guidance, job coaching, and counseling should become a regular part of rehabilitation services for young people recovering from drug addiction in Hong Kong. Vocational guidance and employment support is seldom included in the care of young people recovering from drug addiction. In collaboration with social service agency, we recruited young people who are recovering from addiction and provided a package of vocational assessment and guidance services to them. In this study, we found that most of the participants were motivated and ready to engage in the job market despite their unstable job record. Vocational assessment results helped young people to ascertain that they could meet the demands of entry-level jobs, and help them understand their own strength and limitations in work aptitudes. Most participants had low career maturity and would need assistance in identifying their work interests and in expanding their understanding of occupational groups and job markets, so that they can make more concrete career or education choices.

\section{Acknowledgments}

This study is financially supported by the Youth Outreach Service, Salvation Army of Hong Kong.

\section{Conflict of interest}

None to report.

\section{References}

[1] Platt JJ. Vocational rehabilitation of drug abusers. Psychological Bulletin. 1995;117(3):416.

[2] Room JA. Work and identity in substance abuse recovery. Journal of Substance Abuse Treatment. 1998;15(1):65-74.

[3] Walls RT, Moore LC, Batiste LC, Loy B. Vocational rehabilitation and job accommodations for individuals with substance abuse disorders. Journal of Rehabilitation. 2009;75(4):35.

[4] Sinakhone JK, Hunter BA, Jason LA. Good job, bad job: The employment experiences of women in recovery from substance abuse. Work. 2017;57(2):289-95.

[5] Soeker S, Matimba T, Msimango H, Moswaane B, Tom S. The challenges that employees who abuse substances experience when returning to work after completion of employee assistance programme (EAP). Work. 2016;53(3):569-84.

[6] Narcotics Division, Security Bureau. Central Registry of Drug Abuse. Sixty-sixth Report 2007-2016. 2017. Hong Kong SAR Government.

[7] Henry BL, Minassian A, Perry W. Effect of methamphetamine dependence on everyday functional ability. Addictive behaviors. 2010;35(6):593-8.

[8] Weber E, Blackstone K, Iudicello JE, Morgan EE, Grant I, Moore DJ, Woods SP. Translational Methamphetamine AIDS Research Center (TMARC) Group neurocognitive deficits are associated with unemployment in chronic methamphetamine users. Drug and Alcohol Dependence. 2012;125:146-53. 
[9] Najt P, Fusar-Poli P, Brambilla P. Co-occurring mental and substance abuse disorders: A review on the potential predictors and clinical outcomes. Psychiatry Research. 2011;186(2):159-64.

[10] Johnson ME, Reynolds GL, Fisher DG. Employment status and psychological symptomatology among drug users not currently in treatment. Evaluation and Program Planning. 2001;24(2):215-20.

[11] Renwick RM, Krywonis M. Personal and environmental factors related to employment: Implications for substance abuse intervention. Journal of Rehabilitation. 1992;58(1):23.

[12] Morissette P, De Montigny MJ. Vocational Rehabilitation of Substance Abusers: A Challenge. Responding to the Oppression of Addiction: Canadian Social Work Perspectives. 2003:81.

[13] Labour Department. Youth Employment and Training Programme (YETP). Hong Kong; [Accessed 2017 Jul 21]. Available from: http://www.yes.labour.gov.hk/ypyt/ home.aspx?lang=en

[14] Powers RJ. Enhancement of former drug abusers' career development through structured group counseling. Journal of Counseling Psychology. 1978;25(6):585.

[15] Siegal HA, Fisher JH, Rapp RC, Kelliher CW, Wagner JH, O'Brien WF, Cole PA. Enhancing substance abuse treatment with case management its impact on employment. Journal of Substance Abuse Treatment. 1996;13(2):93-8.

[16] Smith EJ. The strength-based counseling model. The Counseling Psychologist. 2006;34(1):13-79.

[17] Power PW. A Guide to Vocational Assessment. 4th Ed. PROED, Inc., Austin, TX 78757-6897; 2006.

[18] Power PW. A Guide to Vocational Assessment. 5th Ed. PROED, Inc. 8700 Shoal Creek Boulevard, Austin, TX 787576897; 2013:327-336.

[19] Ludden L, Shatkin L. Guide for occupational exploration. Jist Works; 2001.

[20] Harris M, Gladman B, Hennessy N, Lloyd C, Mowry B, Waghorn G. Reliability of a scale of work-related self-efficacy for people with psychiatric disabilities. International Journal of Rehabilitation Research. 2010;33(2): 183-6.

[21] Alfano AM. A scale to measure attitudes toward working. Journal of Vocational Behavior. 1973;3(3):329-33.

[22] Brown L, Sherbenou RJ, Johnsen SK. Test of Nonverbal Intelligence. Third Edition. Pro-Ed, Inc.; 1997.

[23] Athanasiou MS. Current nonverbal assessment instruments: A comparison of psychometric integrity and test fairness. Journal of Psychoeducational Assessment. 2000;18(3): 211-29.

[24] Tiffin J, Asher EJ. The Purdue Pegboard: Norms and studies of reliability and validity. Journal of Applied Psychology. 1948;32(3):234.

[25] VALPAR International Corporation. VALPAR Component Work Samples. Tucson, AZ: VALPAR International Corporation; [Accessed 2017 Jul 21]. Available from: http://www.valparint.com

[26] Christopherson B, Hayes P. VAPLAR component work samples uses in allied health. Valpar International Corporation, Tucson, AZ. 2006.

[27] Ngai EK, Siu AM, Ng BF. Reliability of the Chinese VALPAR Pro3000 Modular Assessment System for Assessing Persons with Mental Illness. Hong Kong Journal of Occupational Therapy. 2011;21(2):50-5.

[28] Career Guidance Section, School Development Division, Education Bureau Guide on Life Planning Education and Career Guidance for Secondary Schools 1st Edition. (May 2014). Hong Kong SAR Government.

[29] Leung SA. Career counseling in Hong Kong: Meeting the social challenges. The Career Development Quarterly. 2002;50(3):237-45.

[30] Hui EK. A whole-school approach to guidance: Hong Kong teachers' perceptions. British Journal of Guidance and Counselling. 2002;30(1):63-80.

[31] Shek DT. Tackling adolescent substance abuse in Hong Kong: Where we should and should not go. The Scientific World Journal. 2007;7:2021-30. 